\title{
Mutated PET117 causes complex IV deficiency and is associated with neurodevelopmental regression and medulla oblongata lesions
}

\author{
G. H. Renkema ${ }^{1}$ - G. Visser ${ }^{2}$ - F. Baertling ${ }^{1,3}$ - L. T. Wintjes ${ }^{1}$ - V. M. Wolters ${ }^{4}$. \\ J. van Montfrans ${ }^{5}$ - G. A. P. de Kort ${ }^{6}$ - P. G. J. Nikkels ${ }^{7} \cdot$ P. M. van Hasselt ${ }^{2}$ \\ S. N. van der Crabben ${ }^{2} \cdot$ R. J. T. Rodenburg ${ }^{1}$
}

Received: 2 February 2017 / Accepted: 31 March 2017 / Published online: 6 April 2017

(C) The Author(s) 2017. This article is an open access publication

\begin{abstract}
The genetic basis of the many progressive, multi systemic, mitochondrial diseases that cause a lack of cellular ATP production is heterogeneous, with defects found both in the mitochondrial genome as well as in the nuclear genome. Many different mutations have been found in the genes encoding subunits of the enzyme complexes of the oxidative phosphorylation system. In addition, mutations in genes encoding proteins involved in the assembly of these complexes are known to cause mitochondrial disorders. Here we describe two sisters with a mitochondrial disease characterized by lesions in the medulla oblongata, as demonstrated by brain magnetic resonance imaging, and an isolated complex IV deficiency and reduced levels of individual complex IV subunits. Whole exome sequencing revealed a homozygous nonsense mutation resulting in a premature stop codon in the gene encoding Pet117, a small protein that has previously been predicted to be a complex IV assembly factor. PETI17 has not been identified as a mitochondrial disease gene before. Lentiviral
\end{abstract}

Electronic supplementary material The online version of this article (doi:10.1007/s00439-017-1794-7) contains supplementary material, which is available to authorized users.

R. J. T. Rodenburg

richard.rodenburg@ radboudumc.nl

1 Department of Pediatrics, 774 Translational Metabolic Laboratory (TML), Radboud Center for Mitochondrial Medicine (RCMM), Radboud University Medical Center, P.O. Box 9101, 6500 HB Nijmegen, The Netherlands

2 Department of Metabolic Diseases, Wilhelmina Children's Hospital, University Medical Center, Utrecht, The Netherlands

3 Department of General Pediatrics, Neonatology and Pediatric Cardiology, Heinrich-Heine-University, Duesseldorf, Germany complementation of patient fibroblasts with wild-type PET117 restored the complex IV deficiency, proving that the gene defect is responsible for the complex IV deficiency in the patients, and indicating a pivotal role of this protein in the proper functioning of complex IV. Although previous studies had suggested a possible role of this protein in the insertion of copper into complex IV, studies in patient fibroblasts could not confirm this. This case presentation thus implicates mutations in PETI17 as a novel cause of mitochondrial disease.

\section{Introduction}

Cellular respiration involves a series of biochemical reactions by which nutrients are oxidized. The energy that is released from these reactions can be used to convert ADP into ATP, the energy currency of the cell. This metabolic pathway takes place in the mitochondria and is executed by the concerted action of several large protein complexes (complex I-IV), called the electron transport chain (ETC), and results in a proton gradient over the mitochondrial

4 Department of Pediatric Gastroenterology, Wilhelmina Children's Hospital, University Medical Center, Utrecht, The Netherlands

5 Department of Pediatric Immunology and Infectious Diseases, Wilhelmina Children's Hospital, University Medical Center, Utrecht, The Netherlands

6 Department of Radiology, University Medical Center, Utrecht, The Netherlands

7 Department of Pathology, University Medical Center, Utrecht, The Netherlands 
inner membrane. This proton gradient is used by complex V, ATP synthase, to drive the production of ATP. The actual use of oxygen takes place at the level of complex IV (cytochrome c oxidase), the final complex of the ETC.

Although the number of patients with a mitochondrial defect is relatively high - with an estimated incidence of at least 1:5000 (Sanderson et al. 2006) - the group is exceptionally heterogeneous, both with regard to the clinical symptoms, as well as to the underlying genetic defects. In general these diseases are progressive, multi system disorders, and usually involve a lack of cellular ATP production (Chinnery and Hudson 2013).

Complex IV deficiency is the second most abundant isolated ETC complex deficiency occurring in 19-27\% of all mitochondrial patients (Debray et al. 2007; Scaglia et al. 2004) and in the majority of cases results in a severe, often fatal, infantile disease. Mammalian complex IV consists of 14 polypeptide chains (Balsa et al. 2012; Pitceathly et al. 2013) of which three are encoded by the mitochondrial DNA (mtDNA) and 11 by the nuclear genome (nDNA)). In addition, complex IV contains two heme groups, two cytochromes, and two copper centers. Only a small proportion of the complex IV deficiencies is caused by mutations in the genes encoding structural complex IV subunits. In rare cases, heteroplasmic mutations are found in the three mtDNA encoded subunits (COXI, COXII, and COXIII) (reviewed in Schon et al. 2012; Shoubridge 2001). More recently, also mutations in some of the nDNA encoded structural subunits have been found associated with disease. These are COX7B (Indrieri et al. 2012), COX6B1 (Abdulhag et al. 2015; Massa et al. 2008), NDUFA4 (Balsa et al. 2012; Pitceathly et al. 2013), COX4-2 (Shteyer et al. 2009), COX6A1 (Tamiya et al. 2014), and COX8A (Hallmann et al. 2016).

Most mutations that result in an isolated complex IV deficiency have been found in genes encoding proteins involved in the many different aspects of the construction of an active complex IV, such as the transcription, translation, and assembly of the subunits, and biosynthesis of heme $a$ and the $\mathrm{Cu}_{\mathrm{A}}$ site of COX2. These genes include COX10, COX14, COX15, COX20, COA5, COA6, SCO1, SCO2, SURF1, TACO1, FASTKD2, LRPPRC, PETIOO (reviewed in Dennerlein and Rehling 2015; Kadenbach and Huttemann 2015; Ng and Turnbull 2016), and most recently COA3 (Ostergaard et al. 2015).

The number of genes encoding assembly factors that are potential mitochondrial disease genes is potentially much larger than the number that has now been identified. Yeast studies have identified more than 34 different complementation groups for nuclear factors involved in complex IV biogenesis (McEwen et al. 1986). These are a subset of the so-called nuclear Pet (petite) genes. Yeast carrying a mutation in a Pet gene has lost the ability to utilize non-fermentable, but not fermentable, carbon sources (McEwen et al. 1986; Tzagoloff and Dieckmann 1990). The homology of the yeast assembly factors with their human counterparts is generally low, making identifications of the human complex IV assembly factors by orthology screening rather difficult. Using ortho-profile, an iterative orthology prediction method, Szklarczyk et al. (2012) predicted several genes encoding potential human complex IV assembly factors. Of some of these their mitochondrial localization had not even been correctly annotated before. On the basis of these predictions, a pathogenic defect in C2orf64/COA5 was detected in a family with fatal cardiomyopathy and complex IV deficiency (Huigsloot et al. 2011).

Since these predictions were made, the involvement of several of these putative assembly factors in complex IV function has been demonstrated. These are C12orf62/ COX14 (Weraarpachai et al. 2012), PET100 (Lim et al. 2014; Olahova et al. 2015), FAM36A/COX20 (Doss et al. 2014; Szklarczyk et al. 2013), and COA3 (Ostergaard et al. 2015), and possibly also PET309/PTCD1, in which a genetic variant was identified by whole exome sequencing of a complex IV deficient patient, although this gene variant has not been functionally characterized yet (Taylor et al. 2014).

Here we describe two sisters born from consanguineous parents who presented with signs of mitochondrial disease. Whole exome sequencing revealed a homozygous mutation in PET117, a putative complex IV assembly factor (McEwen et al. 1993; Szklarczyk et al. 2012) not previously identified as a mitochondrial disease gene.

\section{Materials and methods}

\section{Cell culture}

Fibroblasts were cultured using standard procedures in M199 medium (Gibco) supplemented with $10 \%$ fetal calf serum (FCS, PAA), and $1 \%$ penicillin/streptomycin (Gibco) at $37{ }^{\circ} \mathrm{C}$ with $5 \% \mathrm{CO}_{2}$. Cell lines used were primary fibroblasts, from the patients described here as well as from controls (C).

293FT cells (Invitrogen, Breda, The Netherlands) were grown in Dulbecco's Modified Eagle's Medium (DMEM) containing $4.5 \mathrm{~g} / \mathrm{L}$ glucose, $10 \% \mathrm{FCS}, 4 \mathrm{mM}$ L-glutamine, $1 \mathrm{mM}$ sodium pyruvate, $0.1 \mathrm{mM}$ MEM non-essential amino acids, $1 \%$ penicillin/streptomycin, and $500 \mu \mathrm{g} / \mathrm{ml}$ geneticin (G418). During the transfections for lentivirus production, the medium did not contain penicillin/streptomycin and geneticin. This study adhered to the Declaration of Helsinki and written informed consent was obtained from each individual or their parents. 


\section{Enzyme activity measurements}

The activities of the separate respiratory chain complexes, citrate synthase (CS), and total protein in fibroblasts and muscle biopsies were measured spectrophotometrically as described before (Janssen et al. 2003; Rodenburg 2011) as part of our routine diagnostics. Measurements were only accepted when each of the duplicate values was within a $10 \%$ range of their average. Respiratory chain enzyme activities were normalized on the basis of citrate synthase activity.

\section{Lysates, electrophoresis, and western blotting}

Fibroblasts cell pellets were processed for the analysis of mitochondrial complexes by Blue Native (BN) PAGE as described (Nijtmans et al. 2002). Part of these mitochondrial protein complexes were further processed for SDS-PAGE by adding SDS-PAGE sample buffer. Protein concentrations were measured using a Micro BCA protein assay kit (Thermo Scientific). Mitochondrial extracts were separated on 5-15\% BN-PAGE gels (Nijtmans et al. 2002), or on $10 \%$ SDS-PAGE.

Antisera used were anti-V5 (Invitrogen), anti-COXI (Abcam), anti-COX-II (Invitrogen), anti-COX-IV (Abcam), anti-Porin/VDAC (Mitosciences), anti-CI (NDUFA9) (Abcam), anti-CII (SDHA) (Abcam), and anti-CIII (UCCRC2) (Abcam).

\section{WES analysis and Sanger sequencing}

Whole exome sequencing and data analysis were performed essentially as described before (Neveling et al. 2013; Wortmann et al. 2015). Exome enrichment was performed using the SureSelect Human All Exon $50 \mathrm{Mb}$ Kit (Agilent, Santa Clara, CA, USA). An in-house developed graphical user interface was used for the data visualization and filtering of variants. Several filtering steps were performed on the initial datasets of variants to exclude common polymorphisms (using dbSNP v.137, EVS (http://evs.gs.washington.edu/EVS), ExAC (http:// exac.broadinstitute.org/), and an in-house database) and include only exonic or splice site and non-synonymous mutations. For the clinical interpretation of variants, a routine pipeline was applied to predict the mutation impact at the protein level, which includes the prediction tools SIFT, Polyphen-2, and AlignGVGD (Adzhubei et al. 2010; $\mathrm{Ng}$ and Henikoff 2001; Tavtigian et al. 2006). In addition, genomic conservation as assessed by PhyloP scoring was included in the interpretation of variants (Gilissen et al. 2012; Pollard et al. 2010). We also included database searches into possible protein functions, disease associations and tissue distribution.
The most promising variant was validated by Sanger sequencing in the probands, healthy siblings, and in the parents using the primer pair PET117 exon2_ Fa: tgtaaaacgacggccagtTGGATTTGAATGGCACAAGGATGG and PET117_ exon2_ Ra: caggaaacagctatgaccCTACTAAGCTACTCTCCATCAAC.

\section{Copper treatment}

For copper treatment of patient fibroblasts, a previously published protocol was applied (Salviati et al. 2002) with slight modifications. First, a stock solution of $1000 \mu \mathrm{M}$ $\mathrm{CuCl}_{2}$ was prepared by dissolving $\mathrm{CuCl}_{2}$ (Sigma; 459097) in M199 medium. Final concentrations of $\mathrm{CuCl}_{2}$ were obtained by further diluting the $\mathrm{CuCl}_{2}$ stock solution in M199 medium.

\section{Lentiviral complementation}

Cloning of the constructs and lentiviral transductions were performed as described before (Renkema et al. 2015). In short, a Gateway vector for PET117 without stop codon (gift from Leo Nijtmans) was recombined with the pLenti6.2V5-DEST destination vector (Invitrogen) using the Gateway technology (Invitrogen).

The resulting pLenti6.2-PET117-V5 or the control construct pLenti6.2-AcGFP-V5 was used to produce viruses in HEK 293FT cells. Infections were performed on fibroblasts in $25 \mathrm{~cm}^{2}$ flasks with $1 \mathrm{ml}$ of virus containing supernatant in the presence of $6 \mu \mathrm{g} / \mathrm{ml}$ polybrene (Sigma). Twenty-four hours after infection the medium was refreshed and $48 \mathrm{~h}$ after transduction the selection of transduced cells was started with $2 \mu \mathrm{g} / \mathrm{ml}$ blasticidin (InvivoGen). Cells were selected for 14 days, in which time the mock infected cells (without virus) died. Blasticidin resistant cells were used for biochemical analysis.

\section{Results}

\section{Patient description}

\section{Subject 1}

This patient is the third of six children (individual II-3, Fig. 1, Panel a) born from healthy, second degree consanguineous (mothers of the parents are sisters) Moroccan parents. She was born at term and had a normal start. From the age of 2 years an abnormal motor development was noted. Speech and motor skills slowly regressed from 10 years of age onwards, and she now (at the age of 19 years) only speaks some words. She was examined at the age of 15.6 years, at the time when her younger sister 
a

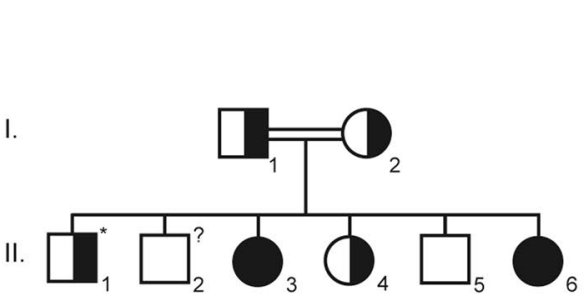

II.

b
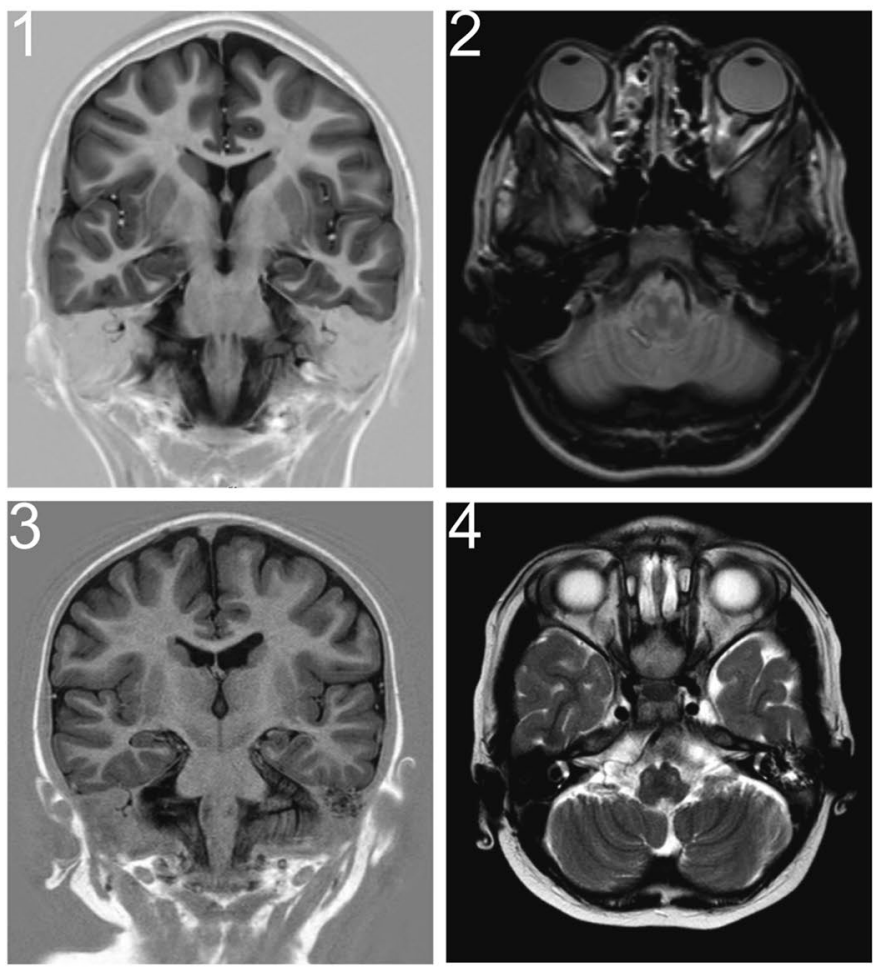

C
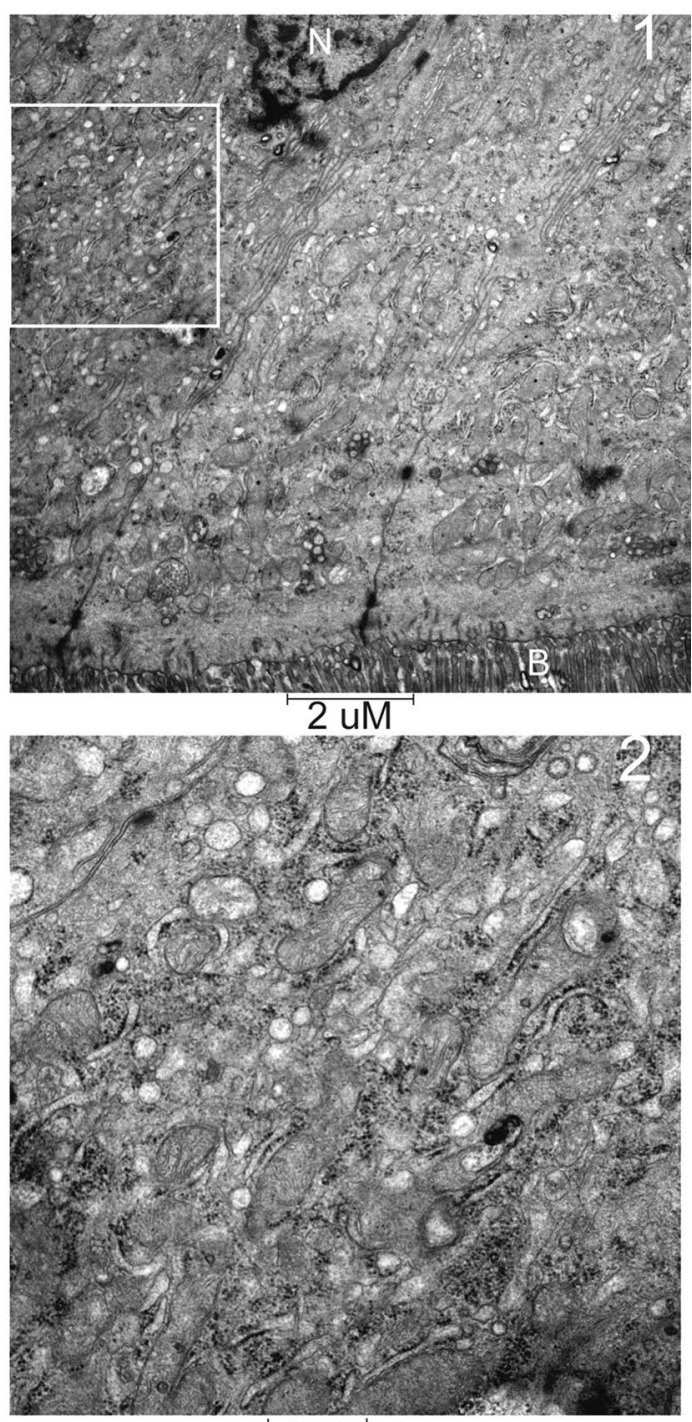

$500 \mathrm{nM}$

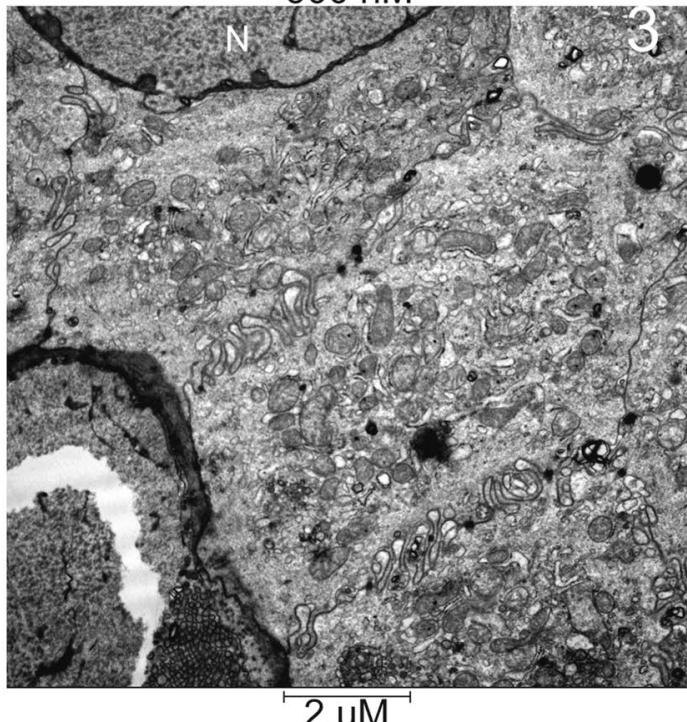


\Fig. 1 Family tree and brain magnetic resonance imaging (MRI) of the affected siblings. a Schematic representation of the family tree. Individual II-2 was lost to follow-up and could, therefore, not be genetically tested. This person is without symptoms. The asterisk marks individual II-1 who has intellectual and motor regression, macrocephaly and adiposity but has no indications of mitochondrial disease and his symptoms are assumed to be unrelated to his PET117 carrier status. Individuals II-3 and II-6 are subjects 1 and 2, respectively. b1 Inversion recovery (IR) MRI, and b2 T2 weighted MRI images are of subject 1 . b3 IR MRI image, and b4 T2 MRI image of subject 2. These images show normal myelination, normal gyral pattern, and normal corpus callosum. Hyperintense areas are noted on the T2 image at the site of the medulla oblongata. c Electron microscopic analysis of the ileum of subject 2 . Increased numbers of mitochondria were noted on the apical (c1, c2 magnification of the indicated region of $\mathrm{c} 1$ ) and the basal (c3) region of the enterocytes. $N$ nucleus, $B$ brush border

(subject 2, see below) showed regression in development. At examination she had a normal growth with normocephaly and no dysmorphic features. On neurological evaluation, pyramidal signs with positive Babinski's, bradykinesia and hypokinesia were noted. An MRI of her brain showed abnormal lesions on the T2 image of the medulla oblongata (Fig. 1, Panels b1 and b2). Extensive ophthalmological examination showed no pathology (light reflex symmetrical, stereo vision according Lang $3 \times$ positive, eye movements normal, funduscopy: papil and macula normal aspect, central minimal tortuous vessels).

Initial metabolic investigation in subject 1 at the age of 13 revealed no abnormalities, apart from a mild elevated plasma glycine levels (375, highest reference value $330 \mu \mathrm{mol} / \mathrm{l}$ ). Four years later more signs of mitochondrial involvement could be noted. In urine, mildly elevated excretion of lactate (159; highest reference value $131 \mathrm{mmol} / \mathrm{mol}$ ), creatine (267; highest reference value $244 \mathrm{mmol} / \mathrm{mol}$ ), and guanidinoacetate (107; highest reference value $78 \mathrm{mmol} / \mathrm{mol}$ ). In plasma, glycine was still mildly elevated $(365 \mu \mathrm{mol} / \mathrm{l})$, with normal CSF/plasma ratio. In addition, lactate levels were elevated (3.0, highest reference value $2.0 \mathrm{mmol} / \mathrm{l})$. Other investigations were normal, including chitotriosidase enzyme activity and transferring isoelectrofocussing. In CSF, elevated levels of alanine (41 $\mu \mathrm{mol} / \mathrm{l}$; highest reference value 29,7$)$ and lactate (3.1; highest reference value $2.1 \mathrm{mmol} / \mathrm{l}$ ) were detected, while other investigations were normal, including 5-methyltetrahydrofolate, 5-hydroxyindolazijnzuur, homovanillic acid, ratio HVA/5HIAA, and 3-O-methyldopamine.

\section{Subject 2}

Subject 2 (individual II-6, Fig. 1, Panel a) is the youngest sister of subject 1 and is currently (2017) 8 years of age. At the age of 20 months she presented for the first time with an episode with fever and diarrhea also with edema and ascites due to protein losing enteropathy
(PLE). She was frequently admitted because of recurrent respiratory infections requiring oxygen and intravenous antibiotic treatment. During viral infections, neutropenia was noted. Additional investigations revealed hypogammaglobulinemia with $\operatorname{IgG} 1$ and $\operatorname{IgG} 2$ subclass deficiency.

Her general development was delayed from birth. From the age of 6 months she suffered from recurring infections and since then her motor development progressed slowed down. Initially this was attributed to her frequent illnesses and hospital admissions. Milestones were all reached at a slightly later age than normal. She was able to walk unaided at $2 \frac{1}{2}$ years. Her exercise tolerance was always lower than her healthy peers. An MRI of the brain at the age of 4 years showed no abnormalities. Motor evaluation at the age of 5 years showed a motor development of a 4-year-old. She has normal facial mimicry, no paresis, and no ataxia. BSIDIII (American norm) at the age of 40 months revealed a developmental age of 27 months (index 74-90). Wechsler Preschool and Primary Scale of Intelligence-third edition (WPPSI-III-NL), at the age of 4 years and 11 months was far below average scores and reference ages, varying from $<2$; 7 years to $<4 ; 10$ years. Currently, she cannot walk stairs anymore, and can only walk unaided for short distances, and has a similar movement disorder as her affected sibling. She is able to speak but her memory declines. An ophtalmological examination showed no pathology, as in subject 1 . The cause of the progressive PLE is as yet unknown, despite extensive investigations, including duodenoscopy, colonoscopy, double balloon enteroscopy, MRI enterography, nuclear albumin scan, laparoscopy, and full thickness biopsy of the ileum and repeat ultrasounds. She initially was treated with extensive immunosuppressive medication and giving supportive therapy consisting of ciproxin and weekly albumin transfusions, as well as intravenous immunoglobulins transfusions a few times per year. The only effective treatment was high-dose prednisone, temporarily reducing her need for albumin transfusions from twice a week to once every 6 weeks. This effect did not last and a partial ileum resection was performed twice, at the age of 4 and 7 years due to severe stenosis of the inflamed ileum. Histological examinations of the ileum revealed diffuse erosions and ulcerations, and (only in the second resection) also arteriovenous malformations in the submucosa of unknown origin. Electron microscopy of the ileum showed increased numbers of mitochondria, both on the apical site (Fig. 1, Panels c1 and c2) as well as on the basal site (Panel c3) of the enterocytes. An MRI of the brain at the age of 6 years revealed two abnormal lesions on the T2 image of the medulla oblongata, identical to those found in subject 1 (Fig. 1, Panels b3 and b4). Based on the MRI findings and the clinical features showing neurodevelopmental regression, a mitochondrial disorder was 
suspected. Metabolic investigations at age 1 year showed no abnormalities in urine, except for excretion of dicarbonic acids probably as result of MCT containing feeding. All other investigations in urine and blood were normal, including lactate, amino acids, acylcarnitine profile. At the age of 5 years, elevated lactate was noted $(3.0 \mathrm{mmol} / \mathrm{l})$. In addition, plasma levels of alanine (1465; highest reference value $600 \mu \mathrm{mol} / \mathrm{l})$ and glycine $(417 \mu \mathrm{mol} / \mathrm{l})$ were observed, with an increased alanine/lysine ratio (6.4; highest reference value 3.0) and alanine:(phenylalanine + tyrosine) ratio (6.6; highest reference value 4.0).

\section{Biochemical characterization of subjects 1 and 2}

Analysis of the OXPHOS complex activities in muscle biopsies from the patients showed an isolated complex IV deficiency as compared to control samples. The activities of the other enzyme complexes were all within the reference range (Table 1).

Complex IV protein expression levels in cultured primary fibroblast cell lines obtained from the patients were compared with those in control cell lines by Blue native (BN)-PAGE separation followed by western blot analysis of the respiratory chain complexes. As shown in Fig. 2, Panel a, the patient fibroblasts had severely reduced amounts of complex IV protein, explaining the reduction in complex IV enzyme activity. The other respiratory chain complexes were present in amounts comparable to those in the control samples, albeit with considerable natural variations as is also apparent in the enzymatic control ranges as shown in Fig. 3, Panel c). Analysis of the complex IV subunits, detected after SDS-PAGE separation followed by western blotting, revealed a severe reduction of the complex IV subunits COX-I, COX-II, and COX-IV in the patient fibroblasts as compared to the levels in a panel of control fibroblasts (Fig. 2, Panel b).

\section{Genetic analysis of subject 1 and 2}

Whole exome sequencing (WES) was used to identify the underlying genetic defect causing the isolated complex IV deficiency. After filtering for common polymorphisms as explained in the materials and methods, we performed a detailed investigation of the variants in the disease genes known to be associated with isolated complex IV deficiency, but this did not reveal any candidate disease causing variants. Subsequently, the genetic variants in the complete WES datasets were compared between the sisters, resulting in three groups of shared variants; compound heterozygous variants, homozygous variants, and variants present in MitoCarta2.0 (Calvo et al. 2016) (shown in Table 2 and Supplementary Table 1 ). To find the most promising disease candidate gene, we analyzed each of the variants for several criteria, as indicated in Supplementary Table 1 and the "Materials and Methods". Based on these criteria a single homozygous variant in PET117 was identified as the only candidate disease causing variant.

A homozygous nonsense mutation in the gene encoding PET117 (NM_001164811) was detected in both patients. The cytosine to thymine $(\mathrm{C}>\mathrm{T})$ mutation at position c. 172 results in a premature stop codon at position 58 of the protein. The mutation was confirmed by Sanger sequencing and cosegregated within the family (Fig. 2, Panel c). This variant is not present in genetic variant databases (dbSNP, EVS, ExAC, in-house database).

\section{Copper treatment of patient cells}

Human PET117 has been identified in a bioinformatics approach to identify human complex IV assembly factors (Szklarczyk et al. 2012). Results from previous studies had indicated that Pet117 may interact with COX17, a mitochondrial copper chaperone for complex IV (Szklarczyk et al. 2012). Therefore, we studied a possible role for Pet117 in the copper insertion into complex IV. For this purpose, we treated the fibroblast cell line from subject 1 with $\mathrm{CuCl}_{2}$. The patient fibroblast were treated for 10 days at concentrations of 100 or $200 \mu \mathrm{M}$, since these conditions have been shown before to lead to a complete (Salviati et al. 2002) or partial (Baertling et al. 2015) rescue of complex deficiency caused by pathogenic variants in genes encoding proteins involved in copper delivery to complex IV. We performed non-denaturing BN-PAGE using $n$-dodecyl $\beta$-D-maltoside lysed mitochondrial protein with subsequent immunoblotting, which revealed no positive effect
Table 1 Isolated complex IV deficiency in muscle biopsies of subject 1 and subject 2

\begin{tabular}{lllllll}
\hline & CI & CII & CIII & CIV & CV & CS \\
\hline Subject 1 & 298 & 456 & 947 & $\mathbf{1 2 3}$ & 719 & 475 \\
Subject 2 & 324 & 412 & 721 & $\mathbf{1 0 3}$ & 809 & 283 \\
Reference range & $163-599$ & $335-888$ & $570-1383$ & $288-954$ & $193-819$ & $151-449$ \\
\hline
\end{tabular}

Activities of all complex activities are expressed as milliunits per unit citrate synthase (mU/U CS). The activity of CS is expressed as milliunits per milligram protein $(\mathrm{mU} / \mathrm{mg})$. Respiratory chain complex activities below the reference range are indicated in bold 


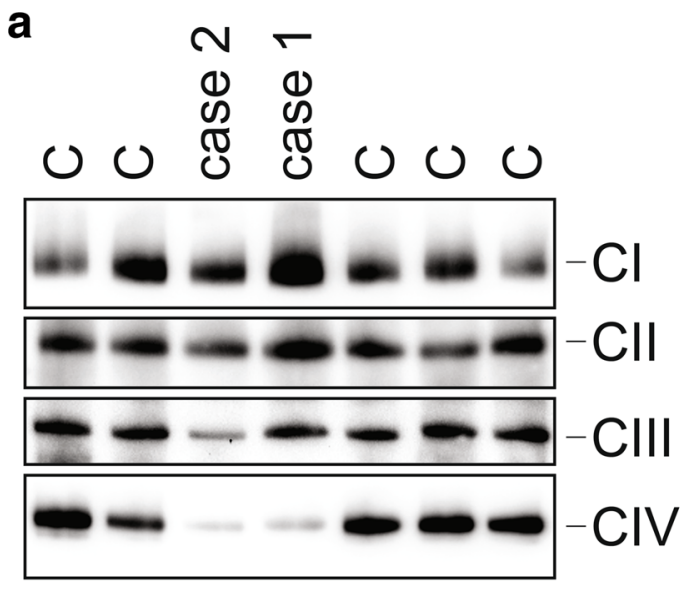

C
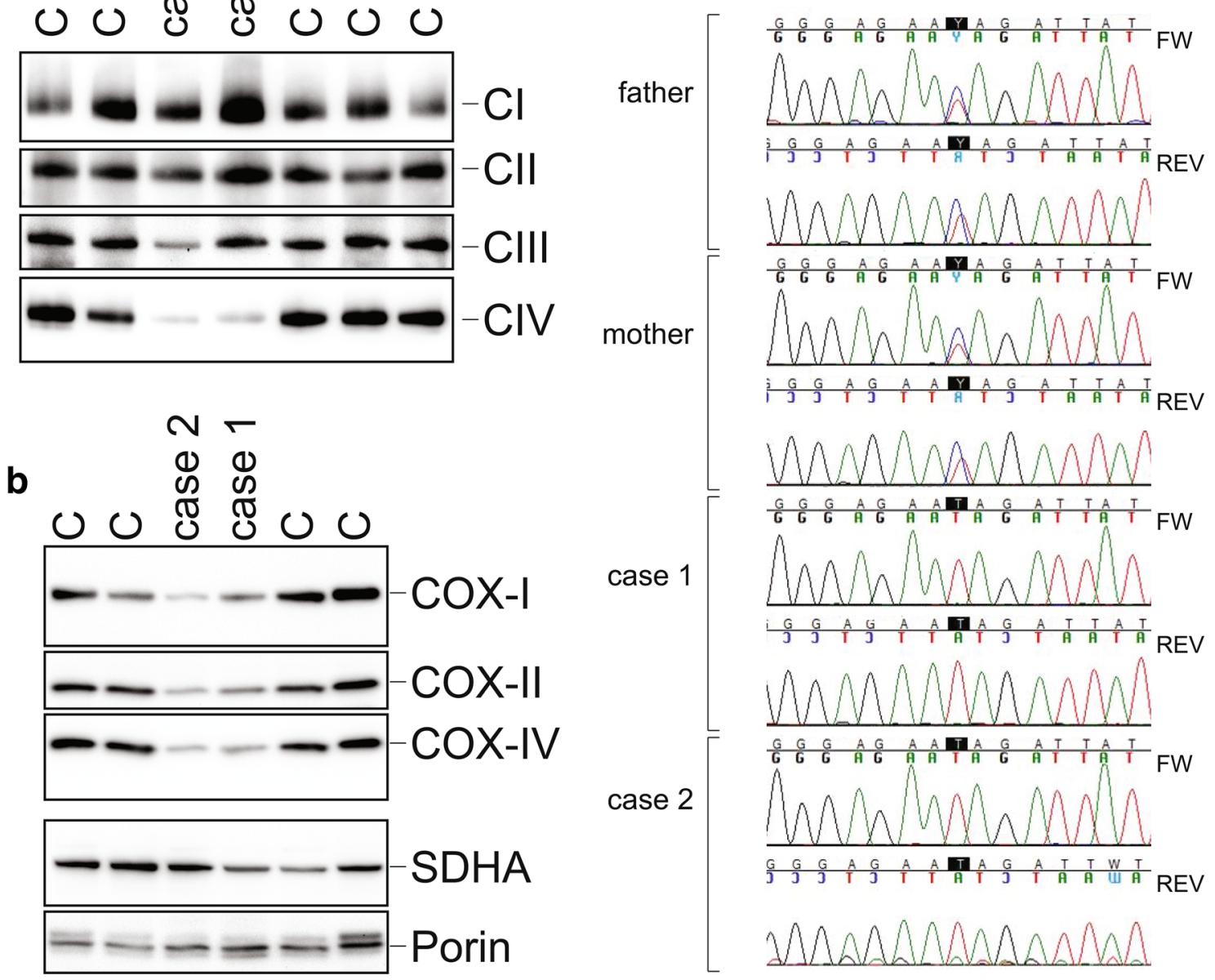

Fig. 2 Patients have reduced levels of complex IV, reduced levels of complex IV subunits, and mutations in PET117. a Blue native electrophoreses and western blot analysis of the patient cell lines compared to three different control cell lines. Blots were probed for complex I (NDUFA9), complex II (SDHA), complex III (UQCRC2), and complex IV (COX-IV). b SDS-PAGE separation of fibroblast extracts

of the two patient cell lines compared to four different control cell lines. Western blots were probed for complex IV subunits, COX-I, COX-II, and COX-IV. Antisera against CII (SDHA) and Porin were used as loading controls. $\mathbf{c}$ Sanger sequencing of DNA of the patients as well as the parents confirmed the presence of the $c .172 \mathrm{C}>\mathrm{T}$ mutation. $F W$ forward sequence, $R E V$ reverse sequence

on complex IV levels in Pet117 deficient patient fibroblasts (data not shown).

\section{Lentiviral complementation}

To establish whether the PETI17 mutation as found in the patients indeed is the cause of the complex IV deficiency in the patients fibroblasts, we performed a genetic complementation of the fibroblasts of subject 1 using lentiviral particles that contain the wild PET117 cDNA with a C-terminal V5-epitope tag. As a control for the procedure we used the gene encoding green fluorescent protein (GFP) also with a C-terminal V5-tag. The expression of the transgene products Pet117-V5 and GFP-V5 was confirmed

by SDS-PAGE and western blot analysis of the fibroblasts cell lines (Fig. 3, Panel a). The apparent molecular masses are consistent with the expected masses of the tagged proteins.

Blue native gel analysis of the respiratory chain complexes showed a clear increase in the levels of fully assembled complex IV in the patient cell line complemented with the wild-type PET117, as compared to the patient cell line transduced with the GFP-V5 expression construct (Fig. 3, Panel b). Activity measurements of the respiratory chain enzymes in these cell lines showed that the expression of wild-type PET117 in the fibroblasts of subject 1 resulted in a concomitant specific and significant increase in the activity of complex IV. The activities of the other respiratory 
a
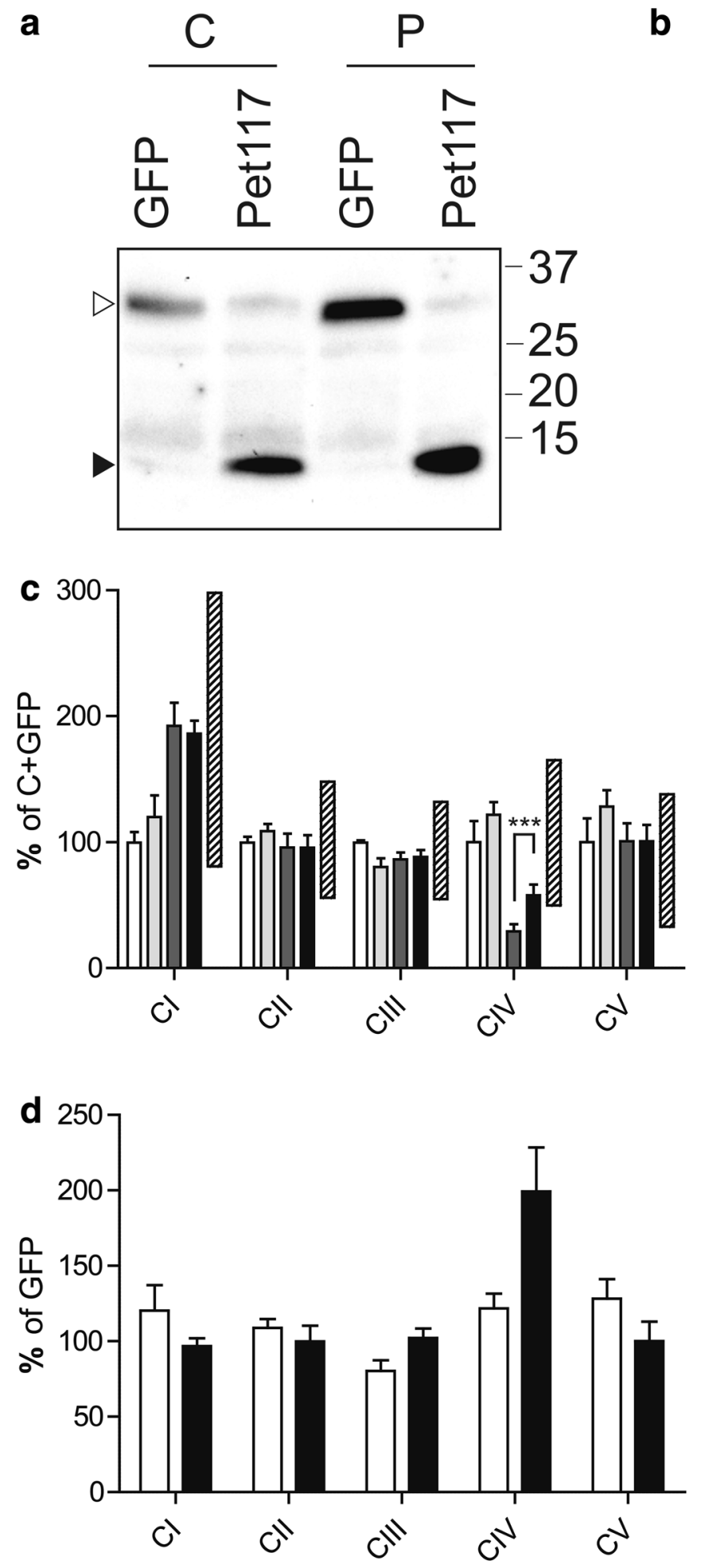

b
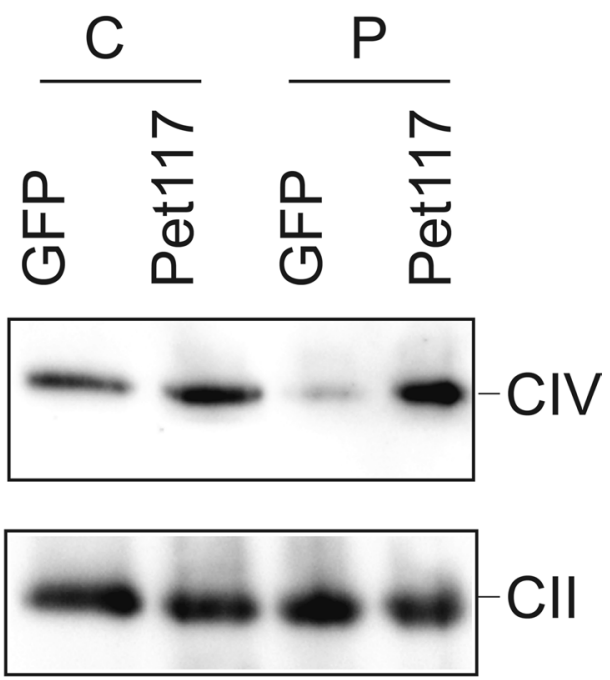

$\square$ C+GFP

$\square$ C+Pet117

$\square$ P+GFP

P+Pet117

WIA range chain enzyme complexes were similar to those in the GFPexpressing patient cell line (Fig. 3, Panels c and d). As indicated by the control ranges based on measurements of 109 different control fibroblast lines, the complex IV enzyme activity of the patient fibroblast was restored to control levels (Panel c).

\section{Discussion}

In this paper we describe two sisters with a mitochondrial disease presenting with neurodevelopmental regression and cerebral lesions in the medulla oblongata. Both 
4Fig. 3 Complementation of fibroblasts with wild-type PET117 restores complex IV activity. Patient subject $1(P)$ and control $(C)$ fibroblasts were transduced with lentiviruses carrying either the wild-type PET117 gene or GFP (green fluorescent protein) as a control, both with a C-terminal V5 tag. a Expression of the transgenes in the stably transduced control $(C)$ and patient $(P)$ fibroblasts was verified after SDS-PAGE separation and western blot detection with anti-V5. GFP-V5 and Pet117-V5 are indicated with open and closed arrow heads, respectively. b Blue native electrophoreses and western blot analysis of the cell lines. Membranes were probed for complex IV (COX-IV) or complex II (SDHA), the latter as a loading control. c The activity of the different respiratory chain complexes and CV were analyzed in three independently obtained mitochondrial extracts from the stably transduced cells. The efficiency of the PET117 complementation is expressed as percentage of the C + GFP complemented cell line. The control ranges of 109 untransduced control fibroblast lines are indicated. $* * * p=0.001$ in an 2-way ANOVA. d Relative increase in activity of the different enzyme complexes compared between the GFP and PET117 transduced cell lines of each individual

patients had an isolated deficiency of complex IV of the respiratory chain. WES analysis of the patients revealed a homozygous variant in PET117 as the most likely cause of the disease, based on the nature of the mutation (nonsense mutation resulting in a premature stop codon), the described mitochondrial localization (Szklarczyk et al. 2012), and the putative involvement in complex IV assembly. We thus report for the first time mutations in PETI17 as a cause for complex IV deficiency.

In addition to the CNS lesions that are present in both patients, in one of the two patients gastrointestinal pathology (PLE) was observed. Electron microscopy revealed increased numbers of mitochondria in intestinal cells of subject 2, which may suggest a mitochondrial involvement, although this may also be a secondary phenomenon due to the intestinal pathology. We considered the possibility of a second mutation in subject 2 as a possible explanation for the intestinal and immunological problems, but a detailed analysis of the WES data, including an analysis of variants that are present in subject 2 but not in subject 1, could not reveal a genetic explanation. As subject 1 does not have these additional symptoms, it remains to be elucidated whether the gastrointestinal and immunological features are part of the mitochondrial disease caused by the PET117 mutation.

The human PETI17 gene has very weak homology with its yeast counterpart and could only be identified from the human genome by a specialized bioinformatics approach (Szklarczyk et al. 2012). The gene, located on chromosome 20 , consists of two exons and encodes for only 81 amino acids. With BLAST searches no homologies with other proteins have been found. Knockout of the yeast PET117 has initially been described as converting a petite phenotype to these cells, pointing to a possible role in mitochondrial function (McEwen et al. 1986, 1993).
The homozygous missense mutation found in the patients results in a premature stop codon. In many cases this does not result in the formation of a truncated protein, but rather leads to nonsense mediated decay. Due to the lack of a specific antiserum to Pet117 we could not analyze the expression of Pet117 in the fibroblast cell lines of these patient. The isolated deficiency of complex IV enzyme activity was accompanied by a specific decrease in holo-complex IV protein levels. The protein expression levels of several individual complex IV subunits were found to be reduced as compared to levels in control fibroblast cell lines. Similar observations have been described for defects in other complex IV assembly factors, such as C12orf62/COX14 (Weraarpachai et al. 2012) and PET100 (Lim et al. 2014; Olahova et al. 2015). This is probably due to increased turnover of the subunits when the assembly of complex IV is impaired.

Our functional complementation studies of the patient cell lines showed that the complex IV activity and protein levels of the assembled complex were restored to nearnormal levels upon transduction with wild-type PET117 cDNA. This proves that the complex IV deficiency is caused by the PETI17 gene defect and indicates a critical role of Pet117 in the biogenesis of complex IV. Although previous studies suggested a possible role of Pet117 in the copper insertion into complex IV, our data indicate that this is not the case. Very recently, a yeast study demonstrated that Pet117 interacts with Cox 15 , the heme $a$ synthase that is an essential factor for complex IV assembly. It was shown that Pet117 is required for oligomerization of Cox15 (Taylor et al. 2016). Previously, it has been shown that Cox 15 forms complexes with Shy1, the yeast homolog of Surf1, and that both proteins form hetero-oligomers and associate with complex IV assembly intermediates and cooperatively insert heme $a$ (Bareth et al. 2013). The recent data indicate that Pet117 is an essential factor in the coupling of heme $a$ synthesis with complex IV assembly (Taylor et al. 2016). This is compatible with our results, showing that a mutation in this gene caused complex IV deficiency and that exclude a role of Pet117 in copper insertion. For future research, it would be of interest to study the heme levels in samples of our patients in more detail, as was done for the Cox 15 patients (Antonicka et al. 2003).

In conclusion, we present two patients with complex IV deficiency caused by mutations in PET117 and thus present a novel genetic cause for mitochondrial disease.

Acknowledgements We thank the mitochondrial diagnostics group (muscle lab, cell culture lab, and DNA lab) of the Radboud Center for Mitochondrial Medicine (RCMM) at the Translational Metabolic Laboratory, RadboudUMC for excellent technical assistance. Lisanne Gommers, Jesse Brunsveld and Marion Antoine are thanked for their contributions. We would like to acknowledge the Genome Technology 
Table 2 Meta data of WES analysis of subject 1 and subject 2

\begin{tabular}{lll}
\hline & Subject 1 & Subject 2 \\
\hline \# Variants called & 128,536 & 78,497 \\
Applied filters & & \\
dbSNP v.137 $(<0.5 \%)$ & 22,768 & 8349 \\
In-house database $(<0.5 \%)$ & 12,239 & 2353 \\
Exonic/splice sites & 1214 & 694 \\
Non-synonymous & 779 & 448 \\
Shared variants & & \\
Compound heterozygous & 12 & \\
Homozygous & 15 & \\
Mitocarta2.0 & 8 & \\
\hline
\end{tabular}

Center at the RadboudUMC and BGI Copenhagen for providing the exome sequencing service. FB was supported by a fellowship the German Research Foundation/Deutsche Forschungsgemeinschaft (Grant no.: 5758/1-1)

\section{Compliance with ethical standards}

Conflict of interest On behalf of all authors, the corresponding author states that there is no conflict of interest.

Open Access This article is distributed under the terms of the Creative Commons Attribution 4.0 International License (http://creativecommons.org/licenses/by/4.0/), which permits unrestricted use, distribution, and reproduction in any medium, provided you give appropriate credit to the original author(s) and the source, provide a link to the Creative Commons license, and indicate if changes were made.

\section{References}

Abdulhag UN, Soiferman D, Schueler-Furman O, Miller C, Shaag A, Elpeleg O, Edvardson S, Saada A (2015) Mitochondrial complex IV deficiency, caused by mutated COX6B1, is associated with encephalomyopathy, hydrocephalus and cardiomyopathy. Eur J Hum Genet 23:159-164

Adzhubei IA, Schmidt S, Peshkin L, Ramensky VE, Gerasimova A, Bork P, Kondrashov AS, Sunyaev SR (2010) A method and server for predicting damaging missense mutations. Nat Methods 7:248-249

Antonicka H, Mattman A, Carlson CG, Glerum DM, Hoffbuhr KC, Leary SC, Kennaway NG, Shoubridge EA (2003) Mutations in COX15 produce a defect in the mitochondrial heme biosynthetic pathway, causing early-onset fatal hypertrophic cardiomyopathy. Am J Hum Genet 72:101-114

Baertling F, van den Brand M, Hertecant JL, Al-Shamsi A, van den Heuvel L, Distelmaier F, Mayatepek E, Smeitink JA, Nijtmans LG, Rodenburg RJ (2015) Mutations in COA6 cause cytochrome c oxidase deficiency and neonatal hypertrophic cardiomyopathy. Hum Mutat 36:34-38

Balsa E, Marco R, Perales-Clemente E, Szklarczyk R, Calvo E, Landazuri MO, Enriquez JA (2012) NDUFA4 is a subunit of complex IV of the mammalian electron transport chain. Cell Metab $16: 378-386$
Bareth B, Dennerlein S, Mick DU, Nikolov M, Urlaub H, Rehling P (2013) The heme a synthase Cox 15 associates with cytochrome c oxidase assembly intermediates during Cox 1 maturation. Mol Cell Biol 33:4128-4137

Calvo SE, Clauser KR, Mootha VK (2016) MitoCarta2.0: an updated inventory of mammalian mitochondrial proteins. Nucl Acids Res 44:D1251-D1257

Chinnery PF, Hudson G (2013) Mitochondrial Genet. Br Med Bull 106:135-159

Debray FG, Lambert M, Chevalier I, Robitaille Y, Decarie JC, Shoubridge EA, Robinson BH, Mitchell GA (2007) Long-term outcome and clinical spectrum of 73 pediatric patients with mitochondrial diseases. Pediatrics 119:722-733

Dennerlein S, Rehling P (2015) Human mitochondrial COX1 assembly into cytochrome c oxidase at a glance. J Cell Sci 128:833-837

Doss S, Lohmann K, Seibler P, Arns B, Klopstock T, Zuhlke C, Freimann K, Winkler S, Lohnau T, Drungowski M, Nurnberg P, Wiegers K, Lohmann E, Naz S, Kasten M, Bohner G, Ramirez A, Endres M, Klein C (2014) Recessive dystonia-ataxia syndrome in a Turkish family caused by a COX20 (FAM36A) mutation. J Neurol 261:207-212

Gilissen C, Hoischen A, Brunner HG, Veltman JA (2012) Disease gene identification strategies for exome sequencing. Eur J Hum Genet 20:490-497

Hallmann K, Kudin AP, Zsurka G, Kornblum C, Reimann J, Stuve B, Waltz S, Hattingen E, Thiele H, Nurnberg P, Rub C, Voos W, Kopatz J, Neumann H, Kunz WS (2016) Loss of the smallest subunit of cytochrome c oxidase, COX8A, causes Leigh-like syndrome and epilepsy. Brain 139:338-345

Huigsloot M, Nijtmans LG, Szklarczyk R, Baars MJ, van den Brand MA, Hendriksfranssen MG, van den Heuvel LP, Smeitink JA, Huynen MA, Rodenburg RJ (2011) A mutation in C2orf64 causes impaired cytochrome c oxidase assembly and mitochondrial cardiomyopathy. Am J Hum Genet 88:488-493

Indrieri A, van Rahden VA, Tiranti V, Morleo M, Iaconis D, Tammaro R, D'Amato I, Conte I, Maystadt I, Demuth S, Zvulunov A, Kutsche K, Zeviani M, Franco B (2012) Mutations in COX7B cause microphthalmia with linear skin lesions, an unconventional mitochondrial disease. Am J Hum Genet 91:942-949

Janssen AJ, Smeitink JA, van den Heuvel LP (2003) Some practical aspects of providing a diagnostic service for respiratory chain defects. Ann Clin Biochem 40:3-8

Kadenbach B, Huttemann M (2015) The subunit composition and function of mammalian cytochrome $\mathrm{c}$ oxidase. Mitochondrion 24:64-76

Lim SC, Smith KR, Stroud DA, Compton AG, Tucker EJ, Dasvarma A, Gandolfo LC, Marum JE, McKenzie M, Peters HL, Mowat D, Procopis PG, Wilcken B, Christodoulou J, Brown GK, Ryan MT, Bahlo M, Thorburn DR (2014) A founder mutation in PET100 causes isolated complex IV deficiency in Lebanese individuals with Leigh syndrome. Am J Hum Genet 94:209-222

Massa V, Fernandez-Vizarra E, Alshahwan S, Bakhsh E, Goffrini P, Ferrero I, Mereghetti P, D'Adamo P, Gasparini P, Zeviani M (2008) Severe infantile encephalomyopathy caused by a mutation in COX6B1, a nucleus-encoded subunit of cytochrome c oxidase. Am J Hum Genet 82:1281-1289

McEwen JE, Ko C, Kloeckner-Gruissem B, Poyton RO (1986) Nuclear functions required for cytochrome-C-oxidase biogenesis in Saccharomyces cerevisiae - characterization of mutants in 34 complementation groups. J Biol Chem 261:11872-11879

McEwen JE, Hong KH, Park S, Preciado GT (1993) Sequence and chromosomal localization of two PET genes required for cytochrome c oxidase assembly in Saccharomyces cerevisiae. Curr Genet 23:9-14 
Neveling K, Feenstra I, Gilissen C, Hoefsloot LH, Kamsteeg EJ, Mensenkamp AR, Rodenburg RJ, Yntema HG, Spruijt L, Vermeer S, Rinne T, van Gassen KL, Bodmer D, Lugtenberg D, de Reuver R, Buijsman W, Derks RC, Wieskamp N, van den Heuvel B, Ligtenberg MJ, Kremer H, Koolen DA, van de Warrenburg BP, Cremers FP, Marcelis CL, Smeitink JA, Wortmann SB, van Zelst-Stams WA, Veltman JA, Brunner HG, Scheffer H, Nelen MR (2013) A post hoc comparison of the utility of sanger sequencing and exome sequencing for the diagnosis of heterogeneous diseases. Hum Mutat 34:1721-1726

Ng PC, Henikoff S (2001) Predicting deleterious amino acid substitutions. Genome Res 11:863-874

Ng YS, Turnbull DM (2016) Mitochondrial disease: genetics and management. J Neurol 263:179-191

Nijtmans LG, Henderson NS, Holt IJ (2002) Blue Native electrophoresis to study mitochondrial and other protein complexes. Methods $26: 327-334$

Olahova M, Haack TB, Alston CL, Houghton JA, He L, Morris AA, Brown GK, McFarland R, Chrzanowska-Lightowlers ZM, Lightowlers RN, Prokisch H, Taylor RW (2015) A truncating PET100 variant causing fatal infantile lactic acidosis and isolated cytochrome c oxidase deficiency. Eur J Hum Genet 23:935-939

Ostergaard E, Weraarpachai W, Ravn K, Born AP, Jonson L, Duno M, Wibrand F, Shoubridge EA, Vissing J (2015) Mutations in COA3 cause isolated complex IV deficiency associated with neuropathy, exercise intolerance, obesity, and short stature. J Med Genet 52:203-207

Pitceathly RD, Rahman S, Wedatilake Y, Polke JM, Cirak S, Foley AR, Sailer A, Hurles ME, Stalker J, Hargreaves I, Woodward CE, Sweeney MG, Muntoni F, Houlden H, Taanman JW, Hanna MG, Consortium UK (2013) NDUFA4 mutations underlie dysfunction of a cytochrome $\mathrm{c}$ oxidase subunit linked to human neurological disease. Cell Rep 3:1795-1805

Pollard KS, Hubisz MJ, Rosenbloom KR, Siepel A (2010) Detection of nonneutral substitution rates on mammalian phylogenies. Genome Res 20:110-121

Renkema GH, Wortmann SB, Smeets RJ, Venselaar H, Antoine M, Visser G, Ben-Omran T, van den Heuvel LP, Timmers HJ, Smeitink JA, Rodenburg RJ (2015) SDHA mutations causing a multisystem mitochondrial disease: novel mutations and genetic overlap with hereditary tumors. Eur J Hum Genet 23:202-209

Rodenburg RJ (2011) Biochemical diagnosis of mitochondrial disorders. J Inherit Metab Dis 34:283-292

Salviati L, Hernandez-Rosa E, Walker WF, Sacconi S, DiMauro S, Schon EA, Davidson MM (2002) Copper supplementation restores cytochrome c oxidase activity in cultured cells from patients with SCO2 mutations. Biochem J 363:321-327

Sanderson S, Green A, Preece MA, Burton H (2006) The incidence of inherited metabolic disorders in the West Midlands, UK. Arch Dis Child 91:896-899

Scaglia F, Towbin JA, Craigen WJ, Belmont JW, Smith EO, Neish SR, Ware SM, Hunter JV, Fernbach SD, Vladutiu GD, Wong LJ, Vogel H (2004) Clinical spectrum, morbidity, and mortality in 113 pediatric patients with mitochondrial disease. Pediatrics 114:925-931
Schon EA, DiMauro S, Hirano M (2012) Human mitochondrial DNA: roles of inherited and somatic mutations. Nat Rev Genet 13:878-890

Shoubridge EA (2001) Cytochrome c oxidase deficiency. Am J Med Genet 106:46-52

Shteyer E, Saada A, Shaag A, Al-Hijawi FA, Kidess R, Revel-Vilk S, Elpeleg O (2009) Exocrine pancreatic insufficiency, dyserythropoietic anemia, and calvarial hyperostosis are caused by a mutation in the COX4I2 gene. Am J Hum Genet 84:412-417

Szklarczyk R, Wanschers BF, Cuypers TD, Esseling JJ, Riemersma M, van den Brand MA, Gloerich J, Lasonder E, van den Heuvel LP, Nijtmans LG, Huynen MA (2012) Iterative orthology prediction uncovers new mitochondrial proteins and identifies C12orf62 as the human ortholog of COX14, a protein involved in the assembly of cytochrome c oxidase. Genome Biol 13:R12

Szklarczyk R, Wanschers BF, Nijtmans LG, Rodenburg RJ, Zschocke J, Dikow N, van den Brand MA, Hendriks-Franssen MG, Gilissen C, Veltman JA, Nooteboom M, Koopman WJ, Willems PH, Smeitink JA, Huynen MA, van den Heuvel LP (2013) A mutation in the FAM36A gene, the human ortholog of COX20, impairs cytochrome c oxidase assembly and is associated with ataxia and muscle hypotonia. Hum Mol Genet 22:656-667

Tamiya G, Makino S, Hayashi M, Abe A, Numakura C, Ueki M, Tanaka A, Ito C, Toshimori K, Ogawa N, Terashima T, Maegawa H, Yanagisawa D, Tooyama I, Tada M, Onodera O, Hayasaka K (2014) A mutation of COX6A1 causes a recessive axonal or mixed form of Charcot-Marie-Tooth disease. Am J Hum Genet 95:294-300

Tavtigian SV, Deffenbaugh AM, Yin L, Judkins T, Scholl T, Samollow PB, de Silva D, Zharkikh A, Thomas A (2006) Comprehensive statistical study of 452 BRCA1 missense substitutions with classification of eight recurrent substitutions as neutral. J Med Genet 43:295-305

Taylor RW, Pyle A, Griffin H, Blakely EL, Duff J, He L, Smertenko T, Alston CL, Neeve VC, Best A, Yarham JW, Kirschner J, Schara U, Talim B, Topaloglu H, Baric I, Holinski-Feder E, Abicht A, Czermin B, Kleinle S, Morris AA, Vassallo G, Gorman GS, Ramesh V, Turnbull DM, Santibanez-Koref M, McFarland R, Horvath R, Chinnery PF (2014) Use of whole-exome sequencing to determine the genetic basis of multiple mitochondrial respiratory chain complex deficiencies. JAMA 312:68-77

Taylor NG, Swenson S, Harris NJ, Germany EM, Fox JL, Khalimonchuk O (2016) The assembly factor Pet117 couples heme a synthase activity to cytochrome oxidase assembly. J Biol Chem 292:1815-1825

Tzagoloff A, Dieckmann CL (1990) Pet genes of Saccharomyces cerevisiae. Microbiol Rev 54:211-225

Weraarpachai W, Sasarman F, Nishimura T, Antonicka H, Aure K, Rotig A, Lombes A, Shoubridge EA (2012) Mutations in C12orf62, a factor that couples COX I synthesis with cytochrome c oxidase assembly, cause fatal neonatal lactic acidosis. Am J Hum Genet 90:142-151

Wortmann SB, Koolen DA, Smeitink JA, van den Heuvel L, Rodenburg RJ (2015) Whole exome sequencing of suspected mitochondrial patients in clinical practice. J Inherit Metab Dis 38:437-443 